Article

\title{
Interaction Effects of Religiosity Level on the Relationship between Religion and Willingness to Donate Organs
}

\author{
Sung Man Yoon 1 \\ Department of Business Administration, Seoul National University of Science and Technology, Seoul 01811, \\ Korea; ysm6123@seoultech.ac.kr
}

Received: 12 November 2018; Accepted: 21 December 2018; Published: 24 December 2018

\begin{abstract}
This study aims to investigate the interaction effect of religiosity level on the relationship between religion and willingness to donate organs. Prior studies have suggested that a high level of religiosity indicates a high level of willingness to donate organs. However, these previous works ignore the interaction effect of the level of religiosity and the doctrinal characteristics of each religion regarding one's own body preservation. Organ donation is an act of transplanting part of one's own body after death to another person and is influenced by the viewpoint of the post-mortem world and the attitude toward the preservation of the body. Therefore, this study analyzes the effects of religious characteristics and belief levels on the relationship between religion and organ donation. Results show that Christianity, such as Catholicism and Protestantism, positively affects the willingness to donate organs as compared with Buddhism. Religiosity level also exerts an interaction effect that strengthens the relationship between Christianity and willingness to donate organs.
\end{abstract}

Keywords: religiosity; religion; organ donation; organ transplantation

\section{Introduction}

Organ transplantation is currently the optimum treatment for patients with terminal organ dysfunction; the development of medical technology has gradually increased the success rate of organ transplantation and rapidly increased the number of patients requiring organ transplants (Choi 2006; Levy 2018). However, the number of registrants who wish to donate tissues is 30,386 in the fourth quarter of 2016 in Korea, compared with 4172 who wish to donate brain tissue, and 1725 who want to donate after donation (Song 2017). As of May 2017, the number of actual donors has been limited to 34 organ donors and 16 post-donors. In general, very few organ donors have pledged to donate (Cho 2018). The disparity between patients in need for an organ and organs donated continues to grow in most parts of the world. The resulting organ shortage has many serious consequences (Levy 2018).

In Korea, organ donation has a lower participation rate than other countries due to ethical problems. The Confucian doctrine of Korea emphasizes the preservation of the "body inherited from parents." However, a difference exists between "caring for others and sharing in the realm of life" as emphasized by the religious types introduced in other countries such as Catholicism and Protestantism. Therefore, in Korea, where Confucianism is dominant, organ donation has high probability to violate the Confucian standard of values that requires "body preservation" (Cho 2017).

Organ donation has three main forms: brain-death donation, post-death donation, and survivor's bio-donation (Cho 2018). Brain-death donation is the case of donating an organ of a person who has been judged to be brain dead due to an accident or a disease. Donation is made by consent before the death or by the application of a family member. Post-death donation is made if the deceased consents to donate organs before death or by the consent of the family members. The third type is the case when 
a living donor donates organs. The method of donation is divided into two cases: one is entrustment to the nation in relation to the selection of the transplant recipients, and the other is the designated donation that decides which organ will be denoted to the transplant recipient.

Religion forms a conscious and ethical consciousness for certain acts in society from the internal state of the individual (Choi 2004). Despite the positive function of religions, some prior studies have suggested that religions are not linked to altruistic attributes such as organ donation intentions (Kim 2003). However, these prior studies have used only religious types as a variable in the analysis model and thus failed to explore the effects of religiosity or religion on organ donation. Other prior studies have suggested that religiosity or religion affects the willingness to donate organs (Kim and Choi 2015; Cho 2017). Although prior studies have shown that religion can affect organ donation, no research results are available on the effect of the level of religiosity on the relationship between religions and organ donation. In other words, prior studies have failed to determine the effect of the changes in the level of religiosity on the level of willingness to donate organs if a person has a religion and a strong belief in that religion.

Therefore, this study aims to investigate whether religiosity or religion affects the willingness to donate organs in addition to socioeconomic or demographic factors. Whether religious people have higher probability of donating organs than non-religious ones and whether high level of religiosity in Buddhism, Protestantism, and Catholicism results in high level of organ donation are examined.

The results of this study provide academic implication that religion exists as an influential factor in the willingness to donate organs and can provide policy implications to various countries that are carrying out various policies to increase organ donation. The remainder of the paper is organized as follows. Section 2 reviews prior literature on the determinants of organ donation and develops the hypotheses. Section 3 presents the empirical research design such as research model, variable measurement, and data selection. Section 4 shows the results of analysis including descriptive statistics, correlation, and regression results. Section 5 discusses implications and policy recommendations.

\section{Literature Review and Hypotheses}

The Studies on the affecting factors of willingness to donate organs in the Korean population have suggested the occupation, donation, and socioeconomic factors. Lee et al. (2017) studied the willingness to donate organs among physicians, nurses, and attorneys and indicated that physicians have the highest level of willingness. In addition, Park et al. (2003) and Lee et al. (2017) explored family, hospital worker, and organ donation experience and showed that the willingness to donate organs of the hospital worker is the highest, and the willingness is affected by the order of the married donor in the family (Park et al. 2003; Lee et al. 2017).

Tsubaki et al. (2018) conducted a meta-analysis of determinants in organ donation intention and reported that the most positive opinion from Spain is $87 \%$, which is in accordance with that obtained by López-Montesinos et al. (2010). On the contrary, the lowest is from Italy with $34 \%$, which is similar to that obtained by Zampieron et al. (2010). Furthermore, Tumin et al. (2013) showed that education is an effective factor to improve the attitude toward organ donation. This attitude is related to whether the family agrees to provide organs. The willingness is also related to discussions within families and periodic blood donation. Meanwhile, Tumin et al. (2013) mentioned that household income and gender are not important factors in organ donation intention.

Recent studies have emphasized the importance of knowledge, education, and publicity for organ donation. In other words, a person who knows the exact process of organ donation increases the probability of organ donation. High belief about organ donation corresponds to high registration rates for organ donation (Steenaart et al. 2018). Seo et al. (2018) analyzed the factors of reluctance to donate organs among families in the state of brain death; failure to accept the brain death status and hope for an active treatment are the main reasons reported by respondents (34.7\%), followed by disagreement among family members (26.3\%), ignorance about organ donation $(16.3 \%)$, and others $(7.5 \%)$. 
The effect of religion on organ donation is still unclear. Kim (2003) suggested that religious variables have a statistically insignificant effect. The reason is that most parents believe in the Korean Confucian thought that the preservation of body is important. Therefore, whether religion affects organ donation and whether the doctrines of Buddhism, Protestantism, and Catholicism are related to organ donation must be examined. Previous results have indicated that Protestants have a statistically significant effect on organ donation intention compared with atheists, but they do not show differences in willingness to donate organs. Cho (2017) used religiosity as a variable in the analysis and showed that strong effect of religion on life corresponds to a high level of willingness to donate organs. On the basis of prior study results, the following hypothesis is made.

Hypothesis 1. A person with a religion has a high level of willingness to donate his or her organs.

The distinction between those who have a religion and those who do not have has no exact level of religiosity. Even if a person has a religion, the person has no difference from a person who does not have a religion unless he or she is very religious. Whether religion is only an altruistic attribute is unknown. In other words, religiosity may be statistically significant because of the differences in religion (Cho 2017). Unlike prior studies, the present work analyzes the relationship between religious belief levels and willingness to donate organs.

In general, religiosity is divided into intrinsic and extrinsic religiosity. Intrinsic religiosity refers to the tendency for an individual to live a life that meets his or her beliefs while having an interest in religion. On the contrary, extrinsic religiosity refers to the tendency of an individual to use religion as a tool for their own purposes (Allport and Ross 1967; Han 2001). Intrinsic religiosity gives individuals the meaning and purpose of life and provides them with satisfaction (Compton 2005). In addition, the spiritual well-being of intrinsic religiosity is an important factor in human happiness and brings closeness to the reality of religion (Argyle 2001). The inner belief in religion implies to overcome the pain of the reality, cope with the difficult situation, pursue satisfactory life, have a positive world view, and help the human mental health (Park et al. 2009). By contrast, the extrinsic aspect of religion is universally experienced in society and culture, and all cultural entities are influenced by intrinsic religiosity (Seol et al. 2012). Religious entities influence human activities in turn. Therefore, people with a high level of religiosity are interested and participate in religious realities, and these activities lead to the meaning and purpose of life (Cho and Lyu 2008).

Intrinsic religiosity can be measured as the degree of subjective religious belief, whereas external religiosity can be defined as the frequencies of prayer activities and religious participation. The levels of intrinsic and extrinsic religiosity can affect the relationship between religion and willingness to donate organs. In Hypothesis 1, a statistically significant relationship exists between religion and willingness to donate organs, and the degree of religiosity may have a statistically significant effect on this relationship. Therefore, the following hypothesis is proposed.

Hypothesis 2. The levels of intrinsic and extrinsic religiosity affect the relationship between religion and willingness to donate organs.

Oliver et al. (2011) reported that, in the European Union, $75 \%$ of the population is Christian including Protestant and Catholic, and the region's organ donation rate is increased to 16.85 per million from 2008. In Iran, $99.58 \%$ are Muslims, and its organ donation rate is 2.9 per million. In Japan, 51\% are Shindo and $42 \%$ are Buddhist. In Israel, $75 \%$ of the population is Jew, and the country's organ donation rate is 9 per 1 million. In Saudi Arabia, 97\% of the population is Muslim, and the region's organ donation rate is 3.3 per million. In Singapore, $42.5 \%$ of the population is Christian, and the country's organ donation rate is 4.6 per million. In the United States, $76 \%$ is Christian. These results indicate that a high number of Christians in a country imply a high rate of organ donation.

Unlike Buddhists, Christians have a high level of organ donation in their respective doctrines. The idea that all of life is suffering (Gonoe), which can be overcome by eight times of virtues, is crucial to 
Buddhism (Tai 2009). Buddhism also regards everything on Earth as transitory and includes teachings of re-birth. In addition, the death process of an individual is regarded as a critical time that should be treated with care and respect, while preserving the physical integrity of a dead body is not considered crucial. However, the concept of brain death is problematic for some Buddhist traditions. Thus, Buddhism is not, at least, positive for organ donation (Cho 2017). On the contrary, Catholic and Protestant doctrines agree that organ donation is an act of selflessness and endorse transplantation (Choi 2004; Cho 2017). Therefore, the following hypothesis is established.

Hypothesis 3. Christians have higher level of willingness to donate their organs than Buddhists.

\section{Research Methodologies and Data}

\subsection{Research Methodologies}

This study implements the logit function to verify the research hypotheses. A probability forecast $p \in[0,1]$ can be mapped uniquely to a real number called the log-odds, $\log i t(p) \in R$, in Equation (1).

$$
\text { Logit }(p)=\log \left(\frac{p}{1-p}\right)
$$

Accordingly, probabilities can be modeled conveniently with well-studied distributions, such as the normal distribution, that are defined on the entire real line (Satopää et al. 2014). In this section, each of $\mathrm{N}$ experts is assumed to provide one probability forecast of a binary-outcome event. These experts are considered to be interchangeable. That is, no forecaster can be distinguished from the others either across or within problems. The experts' forecasts are denoted by $p_{i}$, and $Y_{i}=\operatorname{logit}\left(p_{i}\right)$ for $i=1,2, \ldots$, $N$. As discussed earlier, the log-odds are modeled using a normal distribution centered at the "true log-odds," which have been regressed toward 0 by a factor of $a$. Specifically, $a \geq 1$ is an unknown level of systematic bias, $p$ is the "true probability" to be estimated, and each $\epsilon_{i}$ i.i.d. $\sim N\left(0, \sigma^{2}\right)$ is a random shock with an unknown variance $\sigma^{2}$ on the individual's reported log-odds. If the model is correct, then the event arising from this model will occur with probability $p$. Therefore, $p$ should be regarded as a model parameter that is subject to estimation.

$$
Y_{i}=\log \left(\frac{p}{1-p}\right)^{1 / a}+\varepsilon_{i}
$$

A large value of $a$ indicates a high probability of the log-odds to be regressed toward 0 or a high probability of estimates to be regressed toward 0.5. Therefore, $a=1$ is associated with an accurate forecast, and any $a>1$ is associated with a partially informed and under-confident forecast (Baron et al. 2013). An expert can be overconfident (McKenzie et al. 2008).

Forecasts can be provided at the highest level of self-reported expertise. By contrast, empirical evidence that forecasts as a group tends to lack confidence is presented herein. Therefore, group-level confidence is considered a reasonable modeling constraint. In other words, imposing such assumption on the empirical model is unnecessary because the data can be introduced by sending the data as $a \in[0, \infty]$. Unlike the systematic bias term $a$, the random error component $\epsilon_{i}$ is allowed to vary among experts. Thus, this study obtains Equation (3).

$$
\begin{aligned}
& \log \left(\frac{p_{i}}{1-p_{i}}\right)^{\text {i.i.d. }} \text { Normal }\left(\log \left(\frac{p}{1-p}\right)^{1 / a}, \delta^{2}\right) \Leftrightarrow{\frac{p_{i}}{1-p_{i}}}^{\text {i.i.d. }} \log \text {-Normal }\left(\log \left(\frac{p}{1-p}\right)^{1 / a}, \delta^{2}\right) \\
& \Leftrightarrow p_{i}^{\text {i.i.d. }} \text { Logit-Normal }\left(\log \left(\frac{p}{1-p}\right)^{1 / a}, \delta^{2}\right)
\end{aligned}
$$


This model is clearly based on an idealization of the real world and is therefore an over-simplification. Performing a formal statistical test to determine whether the log-odds in the real-world dataset in this study follow a normal distribution leads to a rejection of the null hypothesis of normality. This result simply reflects the inevitability of slight deviations from normality and the sensitivity of the statistical tests when large sample sizes are involved. However, the assumption of normality is an appropriate approximation. Zhang and Maloney (2012) did not model log-odds using a normal distribution but used the logit-transformation with a linear bias term to model probabilities. Di Bacco et al. (2003) used the logit-normal distribution to model experts' probabilities jointly under different levels of information. In the current study, the logit-normal model serves as a theoretical basis for a clean and justified construction of an efficient aggregator.

On the basis of the theoretical logit model above, empirical models are designed as Equations (4) and (5) to test Hypotheses 1-3. In Equations (4) and (5), the dependent variable WILLINGNESS is a dummy variable indicating the presence or absence of the willingness to donate organs. The interest variables are RELIGION representing Hypothesis 1 and the interaction variable (RELIGION X INT_RELIGIOSITY or RELIGION X EXT_RELIGIOSITY) regarding Hypothesis 2. In particular, Hypothesis 3 contains Buddhism, Catholicism, and Protestantism, which are the detailed variables of RELIGION, and the interaction of each of these religion variables with INT or EXT RELIGIOSITY.

Therefore, if a person with a religion has a high level of willingness to donate organs, then $\beta_{1}$ represents a positive $(+)$ coefficient. If a person with a religion has a high level of willingness to donate organs, then $\beta_{3}$ also shows a positive (+) coefficient. The reason for distinguishing between intrinsic and extrinsic religiosity in Equations (4) and (5) is to analyze the effect of the detailed properties of religiosity on the willingness to donate organs. Control variables are factors that may affect the willingness to donate organs, including trust in government, attitude toward human nature, gender, health status, age, education level, income level, employment status, and family number.

$$
\begin{aligned}
& \text { WILLINGNESS }=\beta_{0}+\beta_{1} \text { RELIGION }+\beta_{2} I N T \_R E L I G I O S I T Y+ \\
& \beta_{3} \text { RELIGION } \times \text { INT_RELIGIOSITY }+\beta_{4} \text { TRUSTGOV }+\beta_{5} \text { HNATURE }+\beta_{6} \text { GENDER }+ \\
& \beta_{7} H E A L T H \_S T A+\beta_{8} A G E+\beta_{9} E D U C+\beta_{10} \log (I N C O M E)+\beta_{11} E M P L Y+\beta_{12} F A M I L Y+\varepsilon \\
& \text { WILLINGNESS }=\beta_{0}+\beta_{1} \text { RELIGION }+\beta_{2} \text { EXT_RELIGIOSITY }+ \\
& \beta_{3} \text { RELIGION } \times \text { EXT_RELIGIOSITY }+\beta_{4} \text { TRUSTGOV }+\beta_{5} \text { HNATURE }+\beta_{6} \text { GENDER } \\
& +\beta_{7} H E A L T H \_S T A+\beta_{8} A G E+\beta_{9} E D U C+\beta_{10} \log (I N C O M E)+\beta_{11} E M P L Y+\beta_{12} F A M I L Y+\varepsilon
\end{aligned}
$$

where,

- WILLINGNESS: Supposing that the respondent comes to become brain-dead, 1 if the respondent has an intention to donate her or his organs to those; 0 otherwise.

- RELIGION: It is classified as Protestant, Catholic, and Buddhist. 1 If the respondent has a religion; 0 otherwise.

- $\quad$ BUDDHISM: 1 if the respondent is Buddhist; 0 otherwise.

- CATHOLIC: 1 if the respondent is Catholic; 0 otherwise.

- PROTESTANTISM: if the respondent is Protestant; 0 otherwise.

- RELIGIOSITY: It is classified as intrinsic and extrinsic religiosity.

- INT (Intrinsic) Religiosity: the three-point scale for the religiousness, "Do you call yourself a strong, or not a very strong follower of your religion?" as follows: 1-“Not very strong," 2-"Somewhat strong," and 3-“Strong."

- EXT (Extrinsic) Religiosity: the eight-point scale for the frequency of attending religious meetings, "How often do you attend religious services?" as follows: 1-“Never," 2-"Less than once a year," 3-“Once a year," 4-"Several times a year," 5-“Once a month," 6-“Twice or three times a month," 7—“'Once a week," and 8-“A few times a week." 
- TRUST_GOV: the four-point scale for the trust on central government officials, "How much do you trust the central government officials?" as follows: 1-“Not at all," 2-“Not very much," 3-“To some extent," and 4-"A great deal."

- H_NATURE: the seven-point scale for the opinion on human nature, "How much do you trust the central government officials?" as follows: 1-"Human nature is basically bad," 2, 3, 4, 5, 6, and 7-"Human nature is basically good."

- GENDER: 1 if the respondent is female; 0 otherwise.

- HEALTH_STA the five-point scale for the health condition, "How would you rate your health?" as follows: 1 - "Very poor," 2, 3, 4, and 5-“Very good."

- AGE: the respondent's age.

- EDUC: the eight-point scale for the highest level of school, "What is the highest level of school you have attended?" as follows: 1-"No Formal School," 2-"Elementary School," 3-“Junior high School," 4-"High School," 5-“University" and 6-"higher or Graduate School Master Course."

- EMPLY: 1 if the respondent is employed; 0 otherwise.

- FAMILY: number of family members.

\subsection{Data}

This empirical analysis is based on a financial panel survey conducted by the Korean General Social Survey (KGSS) in 2016. The KGSS population consists of non-institutionalized Korean residents who are 18 years of age or older and can communicate in Korean. This survey directly selected the required number of persons if a well-defined list of all adult persons was available. If such list was unavailable, this survey selected a set of potential respondents in four stages utilizing an area probability sampling method (Korean General Social Survey 2017). In the current study, the first three stages select the required number of households. The fourth stage selects an eligible person from each selected household. First, the primary sampling unit (PSU) for the 2016 KGSS is a Dong, Eub, or Myon. A total of 100 PSUs are selected for the 2016 KGSS with probability proportional to size. Second, the secondary sampling unit (SSU) is defined as Tong/Ban (for Dong) or Li (for Myun). Each SSU is systematically selected from each chosen PSU with probability proportional to size. Third, after completing the sampling frame for each selected Tong/Ban, a fixed number of Hus is systematically selected. Finally, after compiling a list of adults 18 years of age or older for each selected household, an adult is selected using the last birthday method at the time of interview. The KGSS institutions conducted a survey on the Korean people using these sophisticated statistical sampling methods, obtained prior consent on the use of the questionnaire to the questionnaire participants, and the KGSS agency made this information available to the general public.

In 2016, the total number of survey (interviews) is 1052. The reliability and validity of the questionnaire data of KGSS are officially guaranteed because the questionnaire is conducted through these procedures. Especially, this study has a response rate of $95 \%$ with 999 respondents out of 1052 respondents. In general, the survey requires more than $25 \%$ of the surveyed questionnaires to be valid, and this study has a $95 \%$ response rate (The overall response rate has been lowered due to the willingness to donate organs response.).

\section{Empirical Results}

\subsection{Distribution of Sample, Correlation Analysis, and $t$-Test}

Table 1 shows the sample distribution of 999 respondents. First, $71.87 \%$ (718 persons) of respondents answer that they have willingness to donate organs, $54.35 \%$ of them have religion, $43.65 \%$ (237 persons) are Buddhists, 37.38\% (203 persons) are Protestants, and 18.97\% (103 persons) are Catholics. When asked "Do you call yourself a strong or not a very strong follower of your religion?," $47.7 \%$ (259 persons) of respondents say they are "Strong," 33.89\% (184 persons) say they are "Somewhat strong," and 16.94\% (92 persons) say they are "Not very strong." In addition, 48.65\% (486) of respondents answer "Never" 
to the question "How often do you attend religious services?". This question represents frequency of attending religious meetings. The results show that 13.41\% (134 persons), 12.31\% (123 persons), and $8.21 \%$ (82 persons) answer "Several times a year," "Once a week," and "A few times a week". To the question on the level of trust on government, $45.85 \%$ (458 persons) of respondents answer "Only some confidence," $45.45 \%$ (454 persons) answer "Hardly any confidence at all," and 5.71\% (57 persons) answer "A great deal confidence". The distribution of the remaining (socio-personal) variables is shown in Table A1 of Appendix A.

Table 1. Distribution of survey sample $(N=999)$.

\begin{tabular}{|c|c|c|c|}
\hline & Categories & Frequency & Weight (\%) \\
\hline \multirow{2}{*}{ Willingness to donate organ } & 1 (Yes) & 718 & 71.87 \\
\hline & 0 (No) & 281 & 28.13 \\
\hline \multirow{5}{*}{ Having Religions } & 1 (Yes) & 543 & 54.35 \\
\hline & Buddhism & 237 & 43.65 \\
\hline & Protestantism & 203 & 37.38 \\
\hline & Catholic & 103 & 18.97 \\
\hline & $0(\mathrm{No})$ & 456 & 45.65 \\
\hline \multirow{4}{*}{$\begin{array}{l}\text { Intrinsic Religiosity } \\
\quad(=\text { Belief Level) }\end{array}$} & 1 (Not very strong) & 92 & 16.94 \\
\hline & 2 (Somewhat strong) & 184 & 33.89 \\
\hline & 3 (Strong) & 259 & 47.7 \\
\hline & No response & 8 & 1.47 \\
\hline \multirow{8}{*}{$\begin{array}{l}\text { Extrinsic Religiosity (frequency } \\
\text { of attending religious meetings) }\end{array}$} & 1 (Never) & 486 & 48.65 \\
\hline & 2 (Less than once a year) & 33 & 3.3 \\
\hline & 3 (Once a year) & 52 & 5.21 \\
\hline & 4 (Several times a year) & 134 & 13.41 \\
\hline & 5 (Once a month) & 48 & 4.8 \\
\hline & 6 (A few times a month) & 41 & 4.1 \\
\hline & 7 (Once a week) & 123 & 12.31 \\
\hline & 8 (A few times a week) & 82 & 8.21 \\
\hline \multirow{4}{*}{ Trust on government } & 3 (A great deal confidence) & 57 & 5.71 \\
\hline & 2 (Only some confidence) & 458 & 45.85 \\
\hline & 1 (Hardly any confidence at all) & 454 & 45.45 \\
\hline & No response & 30 & 3 \\
\hline
\end{tabular}

Table 2 shows descriptive statistics of socio-personal variables. Human nature (H_NATURE) has a mean of 4.967 and a median of 5, which means that most respondents perceive it as "Human nature is basically good". GENDER is the mean of 0.548 , which means that women are $54.8 \%$ of all respondents and the mean of health status (HEALTH_STA) is 3.474 and the median is 4, which means that the health condition of the respondent is not bad. The mean of the AGE is 49.586, and the EDUC average is 3.668, indicating that the respondents have a high school or college degree. In addition, the mean of Income level (Log(INCOME)) is 5.677, and the monthly income of the respondents is between 300 and 600 million KRW. The mean of EMPLY is $0.541,54.1 \%$ of the respondents are employed and it consists of up to 8 family members (FAMILY).

Table 2. Descriptive statistics of socio-personal variables.

\begin{tabular}{cccccccc}
\hline Variables & Mean & STD & Min & $\mathbf{Q}^{\text {1st }}$ & Median & $\mathbf{Q}^{\text {3rd }}$ & Max \\
\hline H_NATURE & 4.967 & 1.678 & 1 & 4 & 5 & 6 & 7 \\
GENDER & 0.548 & 0.498 & 0 & 0 & 1 & 1 & 1 \\
HEALTH_STA & 3.474 & 1.209 & 1 & 3 & 4 & 4 & 5 \\
AGE & 49.586 & 18.609 & 18 & 34 & 49 & 64 & 99 \\
EDUC & 3.668 & 1.506 & 1 & 3 & 4 & 5 & 6 \\
Log(INCOME) & 5.677 & 1.058 & 2.303 & 5.193 & 5.858 & 6.328 & 10.404 \\
EMPLY & 0.541 & 0.499 & 0 & 0 & 1 & 1 & 1 \\
FAMILY & 2.621 & 1.268 & 1 & 2 & 3 & 4 & 8 \\
\hline
\end{tabular}

Note 1: The variables are defined as in Equation (5). 
Table 3 shows the Pearson's correlation among the main variables. For the willingness to donate organs (WILLINGNESS), RELIGION has a statistically significant coefficient of 0.066, which indicates that the person with a religion has a high intention of organ donation. In particular, PROTESTANTISM and CATHOLICISM have statistically significant coefficients of 0.078 and 0.053 , respectively. By contrast, BUDDHISM has a statistically insignificant coefficient of -0.033 . This result suggests that Christianity (Protestantism and Catholicism), unlike Buddhism, uses postmortem body to help other people (e.g., devoting one's body to another). Therefore, organ donation is highly influenced by religious doctrine.

Table 3. Correlation among the variables of willingness to donate organ, religion, and religiosity.

\begin{tabular}{|c|c|c|c|c|c|c|}
\hline & WILLINGNESS & (1) & (2) & (3) & (4) & (5) \\
\hline (1) RELIGION & $\begin{array}{c}0.066^{* *} \\
(0.037)\end{array}$ & & & & & \\
\hline (2) BUDDHISM & $\begin{array}{l}-0.033 \\
(0.295)\end{array}$ & $\begin{array}{c}0.505^{* * *} \\
(0.000)\end{array}$ & & & & \\
\hline (3) PROTESTANTISM & $\begin{array}{c}0.078 * * \\
(0.014)\end{array}$ & $\begin{array}{c}0.469^{* * *} \\
(0.000)\end{array}$ & $\begin{array}{c}-0.284^{* * *} \\
(0.000)\end{array}$ & & & \\
\hline (4) CATHOLIC & $\begin{array}{l}0.053 * \\
(0.094)\end{array}$ & $\begin{array}{c}0.291^{* * *} \\
(0.000)\end{array}$ & $\begin{array}{c}-0.176^{* * *} \\
(0.000)\end{array}$ & $\begin{array}{c}-0.164^{* *} \\
(0.000)\end{array}$ & & \\
\hline (5) Intrinsic Religiosity & $\begin{array}{c}0.061 \\
(0.162\end{array}$ & $\begin{array}{c}-0.073 * \\
(0.082)\end{array}$ & $\begin{array}{c}-0.108^{* *} \\
(0.010)\end{array}$ & $\begin{array}{c}0.135^{* * *} \\
(0.001)\end{array}$ & $\begin{array}{c}-0.058 \\
(0.168)\end{array}$ & \\
\hline (6) Extrinsic Religiosity & $\begin{array}{c}0.024 \\
(0.444)\end{array}$ & $\begin{array}{c}0.697^{* * *} \\
(0.000)\end{array}$ & $\begin{array}{c}0.140^{* * *} \\
(0.000)\end{array}$ & $\begin{array}{c}0.569 * * * \\
(0.000)\end{array}$ & $\begin{array}{c}0.190^{* * *} \\
(0.000)\end{array}$ & $\begin{array}{c}0.411^{* * *} \\
(0.000)\end{array}$ \\
\hline
\end{tabular}

Note $1: * * *$, and ${ }^{* * *}$ indicate significance at the $10 \%, 5 \%$, and $1 \%$ levels, respectively, for a two-tailed test.

2: The variables are defined as in Equation (5).

Intrinsic and extrinsic RELIGIOSITY are statistically insignificant. However, intrinsic RELIGIOSITY shows a statistically significant coefficient of -0.073 with RELIGION, indicating that people with a religion recognize that their religious beliefs are weak. On the contrary, extrinsic RELIGIOSITY is consistent with general expectation because it shows a statistically significant coefficient of 0.697 with RELIGION.

Table 4 shows the results for the mean difference of major variables in accordance with the willingness to donate organs. The level of willingness to donate organs is statistically significantly higher in respondents with RELIGION, and PROTESTANTISM, and CATHOLICISM are statistically higher in the willingness to donate organs. However, intrinsic and extrinsic RELIGIOSITY do not differ statistically in terms of the willingness to donate organs. This result implies that intrinsic or extrinsic religiosity does not directly affect the willingness to donate organs but indirectly through mediation of religion.

Table 4. Results of $t$-test by the willingness to donate organs (WILLINGNESS).

\begin{tabular}{|c|c|c|c|c|c|c|}
\hline & \multicolumn{2}{|c|}{ WILLINGNESS $=0$} & \multicolumn{2}{|c|}{ WILLINGNESS $=1$} & \multicolumn{2}{|c|}{ Difference } \\
\hline & Mean (a) & Std Dev & Mean (b) & Std Dev & Mean (a-b) & $t$-Value \\
\hline RELIGION & 0.480 & 0.501 & 0.553 & 0.498 & $-0.073^{* *}$ & -2.07 \\
\hline BUDDHISM & 0.260 & 0.439 & 0.228 & 0.420 & 0.031 & 1.05 \\
\hline PROTESTANTISM & 0.153 & 0.361 & 0.223 & 0.416 & $-0.070^{* * *}$ & -2.63 \\
\hline CATHOLIC & 0.068 & 0.252 & 0.102 & 0.302 & $-0.034 *$ & -1.81 \\
\hline Intrinsic Religiosity & 1.610 & 0.752 & 1.714 & 0.746 & -0.104 & -1.40 \\
\hline Extrinsic Religiosity & 3.146 & 2.854 & 3.285 & 3.093 & -0.139 & -0.78 \\
\hline
\end{tabular}

Note $1: * * *$, and ${ }^{* * *}$ indicate significance at the $10 \%, 5 \%$, and $1 \%$ levels, respectively, for a two-tailed test.

2: The variables are defined as in Equation (5). 
This univariate analysis shows that a relationship exists between simple two sides without controlling other influencing factors of organ donation intention. Thus, the correct relevance must be obtained through multivariate analysis. In particular, whether religiosity affects religion in the willingness to donate organs (interaction effect) must be analyzed.

\subsection{Multivariate Analysis: The Effect of Religiosity Level on the Relationship between Religion and the Willingness to Donate Organ}

Table 5 presents the results of the logit regression model in which dependent variables are defined as willingness to donate organs (WILLINGNESS). In the first column, RELIGION (whether the respondent has a religion such as Buddhism, Catholicism, and Protestantism) has a statistically significant coefficient of $0.365(p<0.05)$. This result indicates that respondents with a religion have a high probability of willingness to donate organs. The coefficients of trust on government (TRUST_GOV) and household total income $\log (\mathrm{INCOME})$ are $0.438(p<0.001)$ and $0.316(p<0.001)$, respectively. A high level of trust on government and a high level of household income indicate a high intention of organ donation. By contrast, AGE has a statistically significant coefficient of $-0.019(p<0.001)$, which implies that young age denotes a high level of willingness to donate organs. These results support Hypothesis 1.

In column 2, which shows results by adding intrinsic religiosity only to the model, a statistically significant coefficient of $0.388(p<0.05)$ is obtained. This finding implies that intrinsic religiosity directly affects the willingness to donate organs. In particular, the interaction variable (RELIGION $X$ RELIGIOSITY LEVEL) has a coefficient of $0.223(p<0.05)$, which indicates that the level of religious belief positively affects the willingness to donate organs via RELIGION. That is, the level of religiosity plays a role in strengthening the relationship between religion and willingness to donate organs. These results support Hypothesis 2.

The coefficients of RELIGIOSITY LEVEL are 0.036 (statistically insignificant) and $0.194(p<0.1$, statistically significant) in column 3 , which includes only extrinsic religiosity. Therefore, unlike intrinsic religiosity, extrinsic religiosity is not related to organ donation intention. In particular, the interaction variable is statistically insignificant with a coefficient of 0.220 , which indicates that extrinsic religiosity does not directly or indirectly affect the willingness to donate organs.

Table 6 shows the results for the difference in the effect of Christianity (Catholicism and Protestantism) on the willingness to donate organs compared with Buddhism. In the first column, CHRISTIANITY shows a statistically significant coefficient of $0.468(p<0.05)$, which implies that Catholicism and Protestantism have a greater impact on the willingness to donate organs than Buddhism. This result supports Hypothesis 3, which shows that the doctrine of Christianity is more familiar with organ donation than the doctrine of Buddhism.

In the second and third columns, intrinsic religiosity shows a statistically significant coefficient of $0.356(p<0.005)$, whereas extrinsic religiosity shows a statistically insignificant coefficient of 0.023 . Intrinsic religiosity shows a statistically significant coefficient of $0.841(p<0.005)$ among the interaction variables, thereby showing the interaction effect of religiosity levels. In particular, the level of religious belief rather than the frequency of participation in religious facilities and events affects the willingness to donate organs. In other words, intrinsic religiosity has a positive interaction effect on the relationship between Christianity and willingness to donate organs. 
Table 5. The effect of religion and religiosity level on the willingness to donate organ.

\begin{tabular}{|c|c|c|c|c|c|c|c|c|c|c|}
\hline & \multicolumn{2}{|c|}{ Religion } & \multicolumn{4}{|c|}{ Intrinsic Religiosity } & \multicolumn{4}{|c|}{ Extrinsic Religiosity } \\
\hline & Estimate & Wald $X^{2}$ & Estimate & Wald $X^{2}$ & Estimate & Wald $X^{2}$ & Estimate & Wald $X^{2}$ & Estimate & Wald $X^{2}$ \\
\hline Intercept & $-1.543 *$ & 3.68 & -1.385 & 1.18 & $-1.451 *$ & 3.21 & $-1.686^{* *}$ & 4.436 & $-1.304 *$ & 2.56 \\
\hline RELIGION & 0.365 ** & 4.34 & & & 0.104 & 0.12 & & & 0.058 & 0.03 \\
\hline RELIGIOSITY LEVEL & & & $0.388 * *$ & 5.20 & 0.524 & 1.48 & 0.036 & 1.071 & $0.194 *$ & 3.25 \\
\hline RELIGION $\times$ RELIGIOSITY LEVEL & & & & & $0.223 * *$ & 4.24 & & & 0.220 & 1.45 \\
\hline TRUST_GOV & $0.438^{* * *}$ & 9.35 & 0.306 & 2.35 & $0.415^{* * *}$ & 8.26 & $0.450 * * *$ & 9.921 & $0.435^{* * *}$ & 9.23 \\
\hline H_NATURE & 0.080 & 2.43 & 0.053 & 0.55 & $0.085 *$ & 2.69 & 0.080 & 2.394 & 0.082 & 2.51 \\
\hline GENDER & 0.246 & 1.97 & 0.051 & 0.04 & 0.232 & 1.74 & 0.270 & 2.377 & 0.245 & 1.93 \\
\hline HEALTH_STA & 0.011 & 0.02 & 0.113 & 0.98 & -0.002 & 0.01 & 0.016 & 0.042 & 0.009 & 0.01 \\
\hline $\mathrm{AGE}$ & $-0.019^{* * *}$ & 8.51 & -0.017 * & 2.93 & $-0.021^{* * *}$ & 9.75 & $-0.018^{* * *}$ & 7.062 & $-0.019 * * *$ & 8.08 \\
\hline EDUC & 0.127 * & 2.97 & 0.227 ** & 4.98 & 0.126 * & 2.86 & 0.128 * & 3.027 & 0.128 * & 2.98 \\
\hline $\log (\mathrm{INCOME})$ & $0.316^{* * *}$ & 8.18 & 0.227 & 2.29 & $0.325^{* * *}$ & 8.44 & $0.331^{* * * *}$ & 9.061 & 0.319 & 8.31 \\
\hline EMPLY & -0.231 & 1.58 & -0.039 & 0.02 & -0.207 & 1.25 & -0.241 & 1.728 & -0.234 & 1.62 \\
\hline FAMILY & -0.008 & 0.01 & -0.144 & 1.67 & -0.015 & 0.03 & -0.006 & 0.006 & -0.002 & 0.01 \\
\hline Likelihood Ratio & \multicolumn{2}{|c|}{$72.80 * * *$} & \multicolumn{2}{|c|}{$\begin{array}{l}-0.147 \\
39.88 * * * \\
1.07\end{array}$} & \multicolumn{2}{|c|}{$77.49^{* * *}$} & \multicolumn{2}{|c|}{$69.14^{* * *}$} & \multicolumn{2}{|c|}{$75.20^{* * *}$} \\
\hline
\end{tabular}

Observations

Note $1: * * *$, and ${ }^{* * *}$ indicate significance at the $10 \%, 5 \%$, and $1 \%$ levels, respectively, for a two-tailed test. 2: The dependent variable is WILLINGESS (willingness to donate organs), and the rest of the variables are defined as in Equation (5).

Table 6. The effect of Christianity and religiosity level on the willingness to donate organ.

\begin{tabular}{|c|c|c|c|c|c|c|c|c|c|c|}
\hline & \multicolumn{2}{|c|}{ Religion } & \multicolumn{4}{|c|}{ Intrinsic Religiosity } & \multicolumn{4}{|c|}{ Extrinsic Religiosity } \\
\hline & Estimate & Wald $X^{2}$ & Estimate & Wald $X^{2}$ & Estimate & Wald $X^{2}$ & Estimate & Wald $X^{2}$ & Estimate & Wald $X^{2}$ \\
\hline Intercept & -1.464 & 1.31 & -1.392 & 1.15 & -0.956 & 0.49 & -1.247 & 0.97 & -1.306 & 1.02 \\
\hline CHRISTIANITY & $0.468^{* *}$ & 5.78 & & & -0.895 & 2.23 & & & 0.100 & 0.03 \\
\hline RELIGIOSITY LEVEL & & & 0.356 ** & 4.31 & -0.093 & 0.15 & 0.023 & 0.20 & -0.076 & 0.65 \\
\hline CHRISTIANITY $\times$ RELIGIOSITY LEVEL & & & & & $0.841^{* *}$ & 5.84 & & & 0.088 & 0.58 \\
\hline TRUST_GOV & $0.410^{* *}$ & 4.27 & 0.309 & 2.38 & $0.392 *$ & 3.61 & $0.368 *$ & 3.52 & $0.414^{* *}$ & 4.32 \\
\hline H_NATURE & 0.043 & 0.36 & 0.047 & 0.43 & 0.069 & 0.87 & 0.035 & 0.24 & 0.043 & 0.34 \\
\hline GENDER & 0.076 & 0.09 & 0.065 & 0.06 & 0.063 & 0.06 & 0.077 & 0.09 & 0.100 & 0.15 \\
\hline HEALTH_STA & 0.144 & 1.61 & 0.114 & 0.98 & 0.133 & 1.29 & 0.137 & 1.44 & 0.159 & 1.88 \\
\hline AGE & -0.015 & 2.07 & $-0.018^{*}$ & 3.12 & $-0.020 *$ & 3.69 & -0.015 & 2.28 & -0.014 & 1.70 \\
\hline EDUC & $0.195^{*}$ & 3.65 & $0.211^{* *}$ & 4.26 & $0.181 *$ & 3.04 & $0.211^{* *}$ & 4.37 & $0.198 *$ & 3.73 \\
\hline Log(INCOME) & $0.262 *$ & 3.16 & $0.260 *$ & 2.95 & $0.267^{*}$ & 3.07 & $0.268 *$ & 3.31 & $0.264^{*}$ & 3.20 \\
\hline EMPLY & -0.083 & 0.10 & -0.021 & 0.01 & -0.042 & 0.02 & -0.049 & 0.04 & -0.091 & 0.12 \\
\hline FAMILY & -0.142 & 1.59 & -0.158 & 1.95 & -0.184 & 2.53 & -0.150 & 1.79 & -0.141 & 1.56 \\
\hline Likelihood Ratio & \multicolumn{2}{|c|}{$41.52 * * *$} & \multicolumn{2}{|c|}{$39.88^{* * *}$} & \multicolumn{2}{|c|}{$48.53^{* * *}$} & \multicolumn{2}{|c|}{$37.59 * * *$} & \multicolumn{2}{|c|}{$41.93^{* * *}$} \\
\hline
\end{tabular}

Note $1:{ }^{* * *}$, and ${ }^{* * *}$ indicate significance at the $10 \%, 5 \%$, and $1 \%$ levels, respectively, for a two-tailed test. 2: The dependent variable is WILLINGESS (willingness to donate organs) and the rest of the variables are defined as in Equation (5). 
Tables 7-9 present the results for the effects of each religion and religiosity level on the willingness to donate organs using religion-specific samples. The results for Buddhist samples in Table 7 indicate that BUDDHISM is statistically insignificant with a coefficient of -0.173 . However, in intrinsic religiosity analysis, BUDDHISM and RELIGIOSITY LEVEL are statistically significant with coefficients of $0.963(p<0.1)$ and $0.790(p<0.001)$, respectively. This result is consistent with those of prior studies. However, the interaction variable (BUDDHISM X RELIGIOSITY LEVEL) is statistically significant with a coefficient of $-0.883(p<0.05)$. This finding implies that a high level of intrinsic religiosity corresponds to a low level of willingness to donate organs. In the case of extrinsic religiosity, all the coefficients are statistically insignificant, which indicates that religion and external religiosity levels of Buddhists have no effect on the intention of organ donation.

Table 7. The effect of Buddhism and religiosity level on the willingness to donate organ.

\begin{tabular}{ccccccc}
\hline & \multicolumn{2}{c}{ Religion } & \multicolumn{2}{c}{ Intrinsic Religiosity } & \multicolumn{2}{c}{ Extrinsic Religiosity } \\
\cline { 2 - 6 } & Estimate & Wald $X^{2}$ & Estimate & Wald $X^{2}$ & Estimate & Wald $X^{2}$ \\
\hline Intercept & $-1.754^{* *}$ & 4.77 & -1.858 & 1.96 & $-1.810^{* *}$ & 5.05 \\
BUDDHISM & -0.173 & 0.79 & $0.963^{*}$ & 2.62 & 0.303 & 0.49 \\
RELIGIOSITY LEVEL & & & $0.790^{* *}$ & 9.70 & 0.058 & 2.34 \\
BUDDHISM $\times$ RELIGIOSITY LEVEL & & & $-0.883^{* *}$ & 6.54 & -0.133 & 1.80 \\
TRUST_GOV & $0.475^{* * *}$ & 10.92 & $0.394^{*}$ & 3.69 & $0.468^{* * *}$ & 10.53 \\
H_NATURE & 0.073 & 2.05 & 0.072 & 0.97 & $0.085^{*}$ & 2.66 \\
GENDER & $0.316^{*}$ & 3.35 & 0.063 & 0.06 & $0.287^{*}$ & 2.66 \\
HEALTH_STA & 0.029 & 0.14 & 0.132 & 1.30 & 0.025 & 0.10 \\
AGE & $-0.015^{* *}$ & 5.66 & $-0.020^{*}$ & 3.62 & $-0.017^{* *}$ & 6.52 \\
EDUC & $0.127^{*}$ & 2.95 & $0.197^{*}$ & 3.63 & $0.124^{*}$ & 2.78 \\
Log(INCOME) & $0.339^{* * *}$ & 9.51 & $0.236^{*}$ & 2.43 & $0.335^{* * *}$ & 9.23 \\
EMPLY & -0.251 & 1.88 & -0.054 & 0.04 & -0.256 & 1.93 \\
FAMILY & -0.002 & 0.00 & -0.173 & 2.31 & -0.007 & 0.01 \\
Likelihood Ratio & $69.22^{* * *}$ & & $49.89 * *$ & & $72.03^{* * *}$ \\
\hline Observations & & & & 999 & & \\
\hline
\end{tabular}

Note $1:{ }^{*}, *$, and ${ }^{* *}$ indicate significance at the $10 \%, 5 \%$, and $1 \%$ levels, respectively, for a two-tailed test. 2: The dependent variable is WILLINGESS (willingness to donate organs), and the rest of the variables are defined as in Equation (5).

Table 8. The effect of Catholic and religiosity level on the willingness to donate organ.

\begin{tabular}{ccccccc}
\hline & \multicolumn{2}{c}{ Religion } & \multicolumn{2}{c}{ Intrinsic Religiosity } & \multicolumn{2}{c}{ Extrinsic Religiosity } \\
\cline { 2 - 7 } & Estimate & Wald $X^{\mathbf{2}}$ & Estimate & Wald $X^{\mathbf{2}}$ & Estimate & Wald $X^{2}$ \\
\hline Intercept & $-1.649^{* *}$ & 4.20 & -1.459 & 1.27 & $-1.676^{* *}$ & 4.31 \\
CATHOLIC & $0.722^{* *}$ & 4.56 & 1.341 & 1.78 & 0.098 & 0.03 \\
RELIGIOSITY LEVEL & & & 0.256 & 2.04 & 0.007 & 0.04 \\
CATHOLIC × RELIGIOSITY LEVEL & & & $1.418^{* *}$ & 3.98 & 0.183 & 2.25 \\
TRUST_GOV & $0.469^{* * *}$ & 10.80 & $0.381^{*}$ & 3.53 & $0.466^{* * *}$ & 10.59 \\
H_NATURE & 0.074 & 2.09 & 0.045 & 0.39 & 0.079 & 2.32 \\
GENDER & $0.310^{*}$ & 3.22 & 0.122 & 0.22 & $0.306^{*}$ & 2.99 \\
HEALTH_STA & 0.023 & 0.09 & 0.126 & 1.17 & 0.017 & 0.05 \\
AGE & $-0.017^{* * *}$ & 7.15 & $-0.018^{*}$ & 3.14 & $-0.018^{* * *}$ & 7.26 \\
EDUC & $0.124^{*}$ & 2.82 & $0.228^{* *}$ & 4.89 & $0.129^{*}$ & 3.01 \\
Log(INCOME) & $0.322^{* * *}$ & 8.50 & $0.244^{*}$ & 2.51 & $0.328^{* * *}$ & 8.75 \\
EMPLY & -0.227 & 1.54 & -0.004 & 0.00 & -0.221 & 1.45 \\
FAMILY & 0.000 & 0 & -0.162 & 2.04 & -0.005 & 0.00 \\
Likelihood Ratio & $73.56^{* * *}$ & \multicolumn{7}{c}{$98.60^{* * *}$} & & $75.89^{* * *}$ & \\
\hline Observations & \multicolumn{7}{c}{999} \\
\hline
\end{tabular}

Note $1: *, * *$, and ${ }^{* * *}$ indicate significance at the $10 \%, 5 \%$, and $1 \%$ levels, respectively, for a two-tailed test. 2: The dependent variable is WILLINGESS (willingness to donate organs), and the rest of the variables are defined as in Equation (5). 
Table 9. The effect of Protestantism and religiosity level on the willingness to donate organ.

\begin{tabular}{ccccccc}
\hline & \multicolumn{2}{c}{ Religion } & \multicolumn{2}{c}{ Intrinsic Religiosity } & \multicolumn{2}{c}{ Extrinsic Religiosity } \\
\cline { 2 - 7 } & Estimate & Wald $X^{2}$ & Estimate & Wald $X^{2}$ & Estimate & Wald $X^{2}$ \\
\hline Intercept & $-1.672^{* *}$ & 4.36 & -1.197 & 0.82 & $-1.663^{* *}$ & 4.32 \\
PROTESTANTISM & $0.376^{*}$ & 2.85 & 0.350 & 0.33 & 0.893 & 2.04 \\
RELIGIOSITY LEVEL & & & 0.280 & 1.77 & 0.024 & 0.38 \\
PROTESTANTISM $\times$ RELIGIOSITY LEVEL & & & $0.277^{* *}$ & 3.63 & 0.097 & 0.95 \\
TRUST_GOV & $0.459^{* * *}$ & 10.28 & 0.305 & 2.32 & $0.4560^{* * *}$ & 10.11 \\
H_NATURE & 0.082 & 2.54 & 0.061 & 0.73 & 0.079 & 2.33 \\
GENDER & 0.264 & 2.29 & 0.028 & 0.01 & 0.257 & 2.12 \\
HEALTH_STA & 0.019 & 0.06 & 0.116 & 1.04 & 0.015 & 0.09 \\
AGE & $-0.017^{* * *}$ & 6.99 & $-0.018^{*}$ & 3.02 & $-0.017^{* * *}$ & 6.83 \\
EDUC & $0.124^{*}$ & 2.79 & $0.2199^{* *}$ & 4.58 & $0.124^{*}$ & 2.81 \\
Log(INCOME) & $0.332^{* * *}$ & 9.09 & $0.220^{*}$ & 2.75 & $0.327^{* * *}$ & 8.86 \\
EMPLY & -0.261 & 2.01 & -0.054 & 0.04 & -0.260 & 2.07 \\
FAMILY & -0.006 & 0.01 & -0.144 & 1.67 & 0.005 & 0.08 \\
Likelihood Ratio & 71.404 & & 40.659 & & 71.993 & \\
\hline Observations & \multicolumn{5}{c}{999} \\
\hline
\end{tabular}

Note $1:{ }^{*}, * *$, and ${ }^{* * *}$ indicate significance at the $10 \%, 5 \%$, and $1 \%$ levels, respectively, for a two-tailed test. 2: The dependent variable is WILLINGESS (willingness to donate organs), and the rest of the variables are defined as in Equation (5).

This result implies that the religion or belief level does not affect the willingness to donate organs because it is influenced by the Buddhist doctrine of preserving and respecting the body after death and reborn in the next life. TRUST_GOV and Log(INCOME), which are control variables, show statistically significant positive coefficients. Conversely, AGE shows a statistically significant negative coefficient.

For the Catholic samples in Table 8, RELIGION has a statistically significant coefficient of 0.722 $(p<0.05)$. This result indicates that respondents with a Catholic religion have a high level of intention of organ donation. This finding supports Hypothesis 3. In the intrinsic religiosity column, the interaction variable (CATHOLIC X RELIGIOSITY LEVEL) has a coefficient of $1.418(p<0.05)$. In other words, a high level of intrinsic religiosity denotes a high probability of willingness to donate organs. Therefore, intrinsic religiosity has an interaction effect on the relationship between Catholicism and willingness to donate organs. These results show that respondents who perceive themselves to be higher in belief level than Buddhists or non-believers are more willing to donate their own bodies (organs) to others.

In the extrinsic religiosity column, CATHOLICISM and the interaction variable are statistically insignificant with coefficients of 0.098 and 0.183 , respectively. The sign of these coefficients is positive, but extrinsic religiosity is statistically insignificant in the interaction effect between CATHOLICISM and willingness to donate organs. That is, having extrinsic religiosity, such as the frequency of participation in religious facilities and events, does not affect the willingness to donate organs.

TRUST_GOV, which is a control variable, has statistically significant coefficients of 0.469 $(p<0.001), 0.381(p<0.1)$, and $0.466(p<0.001)$. Thus, a high level of trust on government implies a high level of willingness to donate organs. GENDER also shows statistically significant coefficients of 0.310 $(p<0.1)$ and $0.306(p<0.1)$ in the first and third columns, respectively. This finding indicates that female respondents are more inclined to organ donation that male ones. Similarly, the coefficients of household total income $\log (\mathrm{INCOME})$ are $0.322(p<0.001), 0.244(p<0.1)$, and $0.328(p<0.001)$. This result shows that a high level of household total income corresponds to a high probability of willingness to donate organs. By contrast, AGE shows statistically significant coefficients of $-0.017(p<0.001),-0.018$ $(p<0.1)$, and $-0.018(p<0.001)$. In particular, old age implies a low level of intention of organ donation. The result is due to that elder groups are highly exposed to Confucian ideas (e.g., the preservation of one's own bodies is the efficacy of one's parents), which is a general culture of Korea.

The results for Protestant samples in Table 9 indicate that PROTESTANTISM and interaction variables are similar. In the first column, PROTESTANTISM has a statistically significant coefficient of $0.376(p<0.1)$, which denotes that the probability of organ donation is high for Protestants. Unlike extrinsic religiosity, which shows statistically insignificant coefficients in the second and third columns, intrinsic religiosity has a statistically significant coefficient of $0.277(p<0.005)$. This finding suggests 
that a high level of belief among Protestants corresponds to a high probability of willingness to donate organs. These results are similar to those for Catholic samples. TRUST_GOV, AGE, EDUC, and $\log (\mathrm{INCOME})$ also have statistically significant coefficients. This result is similar to those in Table 8, which shows the results for Catholic samples.

\section{Discussion and Conclusions}

The study aims to investigate the interaction effect of religious belief level on the relationship between religion and willingness to donate organs. Most prior studies have argued that people with religions have high intention of organ donation. However, the current study determines not only the willingness to donate organs with or without religion but also the level of belief in each religion due to differences in doctrines related to preservation. The results of this study are summarized as follows.

First, respondents with a religion have a high probability of willingness to donate organs. This finding is consistent with those of prior studies, which have indicated that people with a religion have a high level of altruism or a belief that their body will be helpful to others.

Second, religiosity level has an interaction effect that strengthens the relationship between religion and willingness to donate organs. Therefore, a high level of belief in the religion corresponds to a high probability of willingness to donate organs. In the analysis that divided religiosity into intrinsic and extrinsic religiosity, intrinsic religiosity shows interaction effect unlike extrinsic religiosity. This result suggests that a high level of belief in the religion denotes a high level of willingness to donate organs. On the contrary, the frequency of visits to religious facilities or religious events does not affect the willingness to donate organs.

Finally, Christianity such as Catholicism and Protestantism has higher willingness to donate organs than Buddhism. The reason is that the re-birth and endless reincarnation beliefs of Buddhism and the preservation of one's body of Korean Confucian thought have a direct negative impact on organ donation. In the analysis of Christianity, only intrinsic religiosity has an interaction effect on the relationship between religion and willingness to donate organs.

As a discussion of this study, I would like to suggest two points. First, according to the results of this study, organ donation may have a big difference in the composition of each religion in different countries. Especially in countries with many Buddhist believers, the organ donation rate is relatively low. However, this study does not suggest Christianity as a way to activate organ donation to Buddhist countries. Ultimately, these Buddhist countries should increase the organ donation rate by activating other factors besides religion. Second, the results of this study are not limited to Korea. Therefore, it is necessary to examine whether the western countries conduct this analysis and whether the same analysis result appears.

This study analyzes the relationship between each religion and organ donation and the interaction effect of religiosity level. This study is meaningful because it extends the scope of prior studies on the relationship between religion and organ donation. This study also provides a policy implication that the level of each religious feature and religiosity must be considered in government policies around the world to increase the proportion of organ donations in the future.

Funding: This research received no external funding.

Conflicts of Interest: The author declares no conflict of interest.

\section{Appendix A}

The Table A1 below summarizes the questionnaires and responses of the data used in the study. 
Table A1. Distribution of socio-personal questionnaires $(N=999)$.

\begin{tabular}{|c|c|c|c|}
\hline Questionnaires & Categories & Freq. & Weight (\%) \\
\hline \multirow{7}{*}{$\begin{array}{c}\text { Opinion on human } \\
\text { nature }\end{array}$} & 1 (Human nature is basically bad) & 40 & 4 \\
\hline & 2 & 61 & 6.11 \\
\hline & 3 & 81 & 8.11 \\
\hline & 4 & 189 & 18.92 \\
\hline & 5 & 184 & 18.42 \\
\hline & 6 & 222 & 22.22 \\
\hline & 7 (Human nature is basically good) & 222 & 22.22 \\
\hline \multirow{2}{*}{ Gender } & 1 (Female) & 548 & 54.85 \\
\hline & 0 (Male) & 451 & 45.15 \\
\hline \multirow{5}{*}{ health condition } & 5 (Very good) & 224 & 22.42 \\
\hline & 4 & 341 & 34.13 \\
\hline & 3 & 218 & 21.82 \\
\hline & 2 & 134 & 13.41 \\
\hline & 1 (Very poor) & 82 & 8.21 \\
\hline \multirow{7}{*}{ Age } & $1(<20)$ & 201 & 20.12 \\
\hline & $2(30 s)$ & 163 & 16.32 \\
\hline & $3(40 \mathrm{~s})$ & 162 & 16.22 \\
\hline & $4(50 \mathrm{~s})$ & 167 & 16.72 \\
\hline & $5(60 \mathrm{~s})$ & 158 & 15.82 \\
\hline & $6(70 \mathrm{~s})$ & 119 & 11.91 \\
\hline & $7(>80)$ & 29 & 2.9 \\
\hline \multirow{6}{*}{ Highest school level } & 1 (No formal school) & 62 & 6.21 \\
\hline & 2 (Elementary school) & 122 & 12.21 \\
\hline & 3 (Junior high school) & 65 & 6.51 \\
\hline & 4 (High school) & 249 & 24.92 \\
\hline & 5 (University) & 442 & 44.24 \\
\hline & 6 (>Graduate school (Masters)) & 59 & 5.91 \\
\hline \multirow{6}{*}{$\begin{array}{l}\text { Monthly household } \\
\text { income }\end{array}$} & 0-150 Korean 10,000 won & 212 & 21.22 \\
\hline & $151-300$ Korean 10,000 won & 213 & 21.32 \\
\hline & 301-600 Korean 10,000 won & 290 & 29.03 \\
\hline & $601-2000$ Korean 10,000 won & 194 & 19.42 \\
\hline & >2000 Korean 10,000 won & 12 & 1.2 \\
\hline & No response & 78 & 7.81 \\
\hline \multirow{2}{*}{ Employment status } & 1 (Employed) & 540 & 54.05 \\
\hline & 0 (Not employed) & 459 & 45.95 \\
\hline \multirow{3}{*}{$\begin{array}{l}\text { Number of family } \\
\text { members }\end{array}$} & $1-2$ & 495 & 49.55 \\
\hline & $3-5$ & 483 & 48.35 \\
\hline & $>5$ & 21 & 2.1 \\
\hline
\end{tabular}

\section{References}

Allport, Gordon W., and J. Michael Ross. 1967. Personal religious orientation and prejudice. Journal of Personality and Social Psychology 5: 432-43. [CrossRef] [PubMed]

Argyle, Michael. 2001. The Psychology of Happiness. London: Routledge.

Baron, Jonathan, Barbara A. Mellers, Philip E. Tetlock, Eric Stone, and Lyle H. Ungar. 2013. Two reasons to make aggregated probability forecasts more extreme. Decision Analysis 11: 133-45. [CrossRef]

Cho, Kwang Deok. 2017. The Influence of Religion and Religious Affiliation to Organ Donation. Theology and Society 31: 129-64. (In Korean)

Cho, Won-Hyun. 2018. Status of Organ Donation and Solution of Organ Shortage in Korea. Journal of Korean Society for Transplant 32: 38-48. (In Korean)[CrossRef]

Cho, Balkeuni, and Jeong Hee Lyu. 2008. The Relations between catholic youth's Religiosity and Well-being: In Archdiocese of Gwang-ju. Studies in Religion 51: 193-225. (In Korean) 
Choi, Jongryul. 2004. An Interpretation of Durkheim's The Elementary Forms of Religious Life from Discourse Theory: Beyond a Neo-Durkheimian Cultural Sociology. Korean Journal of Sociology 38: 1-31. (In Korean)

Choi, Jae Duk. 2006. The Foundation of Organ Donation, A study based on the New Testament and the related literatures. Korea Presbyterian Journal of Theology 26: 69-95. (In Korean)

Compton, William C. 2005. Introduction to Positive Psychology. Belmont: Thomson Wadsworth.

Di Bacco, Mario, Patrizio Frederic, and Frank Lad. 2003. Learning from the Probability Assertions of Experts. Working Paper. Bologna: University of Bologna.

Han, Naechang. 2001. Evaluation of I/E and Other Religiosity Measure in Korea. Korean Journal of Sociology 35: 193-215. (In Korean)

Korean General Social Survey. 2017. 2013-2016 Cumulative Codebook. Available online: http://kgss.skku.edu/ ?page_id=41 (accessed on 2 November 2018). (In Korean)

Kim, Dong Jin. 2003. Factors Affecting Attitudes to Organ Donation. Health and Social Welfare Review 33: 96-135. (In Korean)

Kim, Eun A., and So Eun Choi. 2015. Structural Equation Modeling on Living and Brain Death Organ Donation Intention in Nursing Students. Journal of Korean Academic Nursing 45: 802-11. [CrossRef]

Lee, Eun Woo, Hye Yeon Jang, Sang Youb Han, Kum Hyun Han, Se Won Oh, and Young-Nam Roh. 2017. Influencing Factors Affecting Successful Organ Donation and Families' Consent to Donate after Drain Death. Journal of Korean Society for Transplant 31: 43-48. (In Korean)[CrossRef]

Levy, Mélanie. 2018. State incentives to promote organ donation: Honoring the principles of reciprocity and solidarity inherent in the gift relationship. Journal of Law and the Biosciences 5: 398-435. [CrossRef] [PubMed]

López-Montesinos, Maria Jose, Manzanera Saura, Marzena Mikla, Arz Ríos, Ana Isabel López-Navas, Laura Martínez-Alarcón, Migual Rodríguezb, and Pablo Ramírez. 2010. Organ Donation and Transplantation Training for Future Professional Nurses as a Health and Social Awareness Policy. Transplantation Proceedings 42: 239-42. [CrossRef] [PubMed]

McKenzie, Craig R., Michael J. Liersch, and Ilan Yaniv. 2008. Overconfidence in interval estimates: What does expertise buy you? Organizational Behavior and Human Decision Processes 107: 179-91. [CrossRef]

Oliver, Michael, Alexander Woywodt, Aimun Ahmed, and Imran Saif. 2011. Organ donation, transplantation and religion. Nephrology Dialysis Transplantation 26: 437-44. [CrossRef] [PubMed]

Park, Chang Kyun, Kwang Min Park, Young Joo Lee, Shin Hwang, Ki Hun Kim, Chul Soo Ahn, Deok Bog Moon, Ki Bong Oh, Sung Hun Cho, Tae Yong Ha, and et al. 2003. Analysis for Influencing Factor of the Organ Procurement Rate in Brain Dead Donors. Journal of Korean Society for Transplantation 14: 220-26. (In Korean)

Park, Jun Seong, Park Eun Mi, and Tae Yun Jung. 2009. The influence of religiosity on general trust, self-efficacy, and life-satisfaction-A comparison between Protestants and non-believers in life-style. Studies in Religion 55: 159-90. (In Korean)

Satopää, Ville A., Jonathan Baron, Dean P. Foster, Barbara A. Mellers, Philip E. Tetlock, and Lyle H. Ungar. 2014. Combining multiple probability predictions using a simple logit model. International Journal of Forecasting 30: 344-56. [CrossRef]

Seo, Jinwoo, Youngsun Jeong, Hyungin Kang, Sunhee Kim, and Wonhyun Cho. 2018. Causes of Rejection for Organ Donation by Family of Deceased Donor. Transplantation 102: S761. [CrossRef]

Seol, Kyoung Ok, Ji Eun Park, and Sun Young Park. 2012. Religiosity and Mental Health: A Meta-Analytic Review (1995-2011). Korean Journal of Psychology: General 31: 617-42. (In Korean)

Song, Yoon Jin. 2017. Problems and Alternatives of the Decision-Making for Organ Donation in Korea. Korean Journal of Medical Ethics 20: 176-92. (In Korean)

Steenaart, Esther, Rik Crutzen, and Nanne K. de Vries. 2018. The complexity of organ donation registration: Determinants of registration behavior among lower-educated adolescents. Transplantation Proceedings 50: 2911-23. [CrossRef]

Tai, Michael Cheng-Tek. 2009. An Asian perspective on organ transplantation. Wiener Medizinische Wochenschrift 159: 452-56. [CrossRef]

Tsubaki, Michihiro, Shusuke Tougo, Masahiro Kobayashi, Satoru Arakawa, Yoshiyasu Ito, and Kazunari Yoshida. 2018. A META-ANALYSIS ON ATTITUDES TOWARDS ORGAN DONATION OF UNDERGRADUATE NURSE STUDENTS. Nephrology Dialysis Transplantation 33: 615. [CrossRef] 
Tumin, Makmor, Abdillah Noh, Idris Jajri, Chin-Sieng Chong, Rishya Manikam, and Nawi Abdullah. 2013. Factors that Hinder Organ Donation: Religio-Cultural or Lack of Information and Trust. Experimental and Clinical Transplantation 11: 207-10. [CrossRef]

Zampieron, Alessandra, Marilisa Corso, and Anna Chiara Frigo. 2010. Undergraduate nursing students' attitudes towards organ donation: A survey in an Italian university. International Nursing Review 57: 370-76. [CrossRef]

Zhang, Hang, and Laurence T. Maloney. 2012. Ubiquitous log odds: A common representation of probability and frequency distortion in perception, action, and cognition. Frontiers in Neuroscience 6: 1-14. [CrossRef]

(c) 2018 by the author. Licensee MDPI, Basel, Switzerland. This article is an open access article distributed under the terms and conditions of the Creative Commons Attribution (CC BY) license (http:/ / creativecommons.org/licenses/by/4.0/). 